\title{
Investigations for modelling hardness of biomedical implant during replication of FDM-based patterns by vacuum moulding
}

\author{
RUPINDER SINGH* and GURINDER SINGH \\ Department of Production Engineering, Guru Nanak Dev Engineering College, Ludhiana, Punjab 141006, India \\ e-mail: rupindersingh78@yahoo.com; singhrupinde@gndec.ac.in
}

MS received 19 December 2014; revised 29 May 2016; accepted 27 September 2016

\begin{abstract}
In the present work, effort has been made for modelling the microhardness of biomedical implant prepared by combining fused deposition modelling, vacuum moulding and stir casting (SC) process. A dynamic condylar screw (DCS) plate was selected as a real '3D' biomedical implant for this case study. The DCS plate, made of acrylonitrile butadiene styrene material, was fabricated as a master pattern by fused deposition modelling. After preparation of the master pattern, the mould cavity was fabricated by the vacuum moulding process. Finally a metal-matrix composite of $\mathrm{Al}$ and $\mathrm{Al}_{2} \mathrm{O}_{3}$ prepared by SC process has been poured in the vacuum mould for fabrication of DCS plate. This study outlines the replication procedure of DCS plate in detail from the master pattern to final product. The contribution of the paper is towards finding out the effect and optimum values of three different process parameters (namely: percentage composition of $\mathrm{Al}$ and $\mathrm{Al}_{2} \mathrm{O}_{3}$, vacuum pressure and grain size of silica) towards microhardness of the DCS plate manufactured by the combined process.
\end{abstract}

Keywords. Dynamic condylar screw; acrylonitrile butadiene styrene; fused deposition modelling; metalmatrix composite; vacuum moulding; hardness.

\section{Introduction}

The term 'composite' broadly refers to a material that is composed of a discrete reinforcement distributed in a matrix and it derives its distinguishing characteristics from the properties of its constituents, from the geometry and architecture of the constituents and from the properties of the interfaces between different constituents [1]. Conventional materials have limitations in achieving good combinations of strength, hardness, stiffness, toughness and density. To overcome these shortcomings and to meet the ever-increasing demand of modern day technology, metalmatrix composites (MMCs) are the most promising materials of recent interest [2].

Several investigators have reported that the incorporation of hard particles such as $\mathrm{Al}_{2} \mathrm{O}_{3}$ or $\mathrm{SiC}$ in cast zinc-aluminium alloys improves the sliding and abrasive wear resistance of these alloys for various industrial applications $[3,4]$. The bones of the human body and there implants are different in shape and size [5]. The major requirement of biomedical implants to be used in human body is their biocompatibility [6]. It would be useful if bone implants could be custom made economically for the patient using a medical CT scan. Rapid prototyping techniques can be used to fabricate dimensionally accurate prototypes [7].

*For correspondence
A set of CT images can be converted into a 3D, digital model using a conversion software such as MIMIC8. The input to this software is usually in the form of 'DICOM' files and output is STL, which can be directly used in a fused deposition modelling (FDM) machine to produce a real pattern. Some researchers have highlighted the mechanical behaviour of biomedical implants fabricated by the vacuum moulding $(\mathrm{VM})$ process [8].

Figures 1 and 2, respectively, show schematics of FDM and VM processes. A pattern made from wood is normally used in the VM process. The VM process is different from conventional sand casting, as this process does not require any binder for sand holding. In this process, a polymer sheet is used to seal the open ends of the mould $[9,10]$. Literature review reveals that a lot of work has been reported on the optimization of FDM, SC and VM processes and their various parameters like pouring temperature, film thickness and jolting time for producing sound casting [11-13]. But hitherto no work has been reported on modelling the hardness of biocompatible implants prepared by the replication of FDM-based acrylonitrile butadiene styrene (ABS) patterns and combining with VM and SC processes. In the present research work, investigations have been made for modelling the hardness of biocompatible implant prepared by replication of FDM-based patterns by combining VM and SC processes. The biomedical component selected for this study is a DCS (dynamic condylar screw) plate (see figure 3). It is used for internal fixation of 


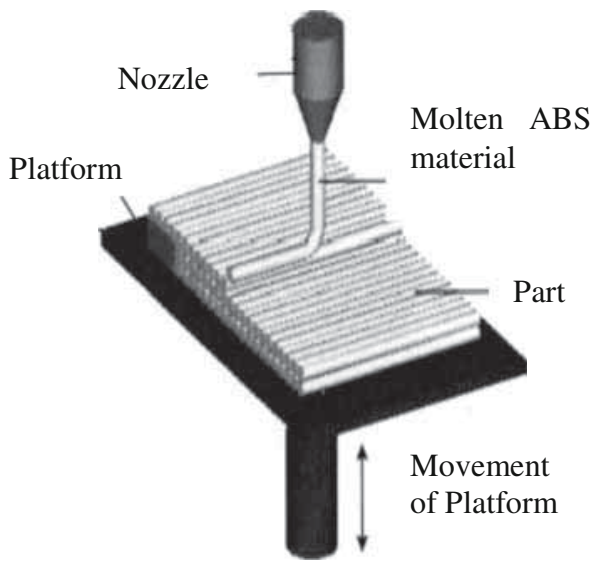

Figure 1. Schematic of FDM [8].

certain distal femoral and sub-trochanteric fractures. DCP holes in the DCS side plate allow angulations of $4.5 \mathrm{~mm}$ cortex screws and axial compression across a shaft fracture.
Figures 4, 5 and 6, respectively, show the use of DCS plate for the fixation of distal femoral and sub-trochanteric fractures, and a 3D view of DCS [8].

\section{Experimentation}

For conducting the pilot experimentation, different percentages composition of $\mathrm{Al}_{2} \mathrm{O}_{3}$ in $\mathrm{Al}$, vacuum pressure (250-450 $\mathrm{mm}$ of $\mathrm{Hg}$ ) and silica sand of grain size 50-70 were used. Commercially pure $\mathrm{Al}$ was melted in a silicongraphite crucible in an electric furnace. The selection of input process parameters was initially based upon previous reported literature $[11,12]$ followed by counter-verification during trial runs. For example, as regards percentage composition of $\mathrm{Al}_{2} \mathrm{O}_{3}$ in $\mathrm{Al}$, it was observed that below $5 \%$ of $\mathrm{Al}_{2} \mathrm{O}_{3}$ in $\mathrm{Al}$ the change in microhardness values was not evident. Similarly when proportion of $\mathrm{Al}_{2} \mathrm{O}_{3}$ in $\mathrm{Al}$ was raised above $10 \%$ again no change in hardness was observed. This may be because of improper mixing. It

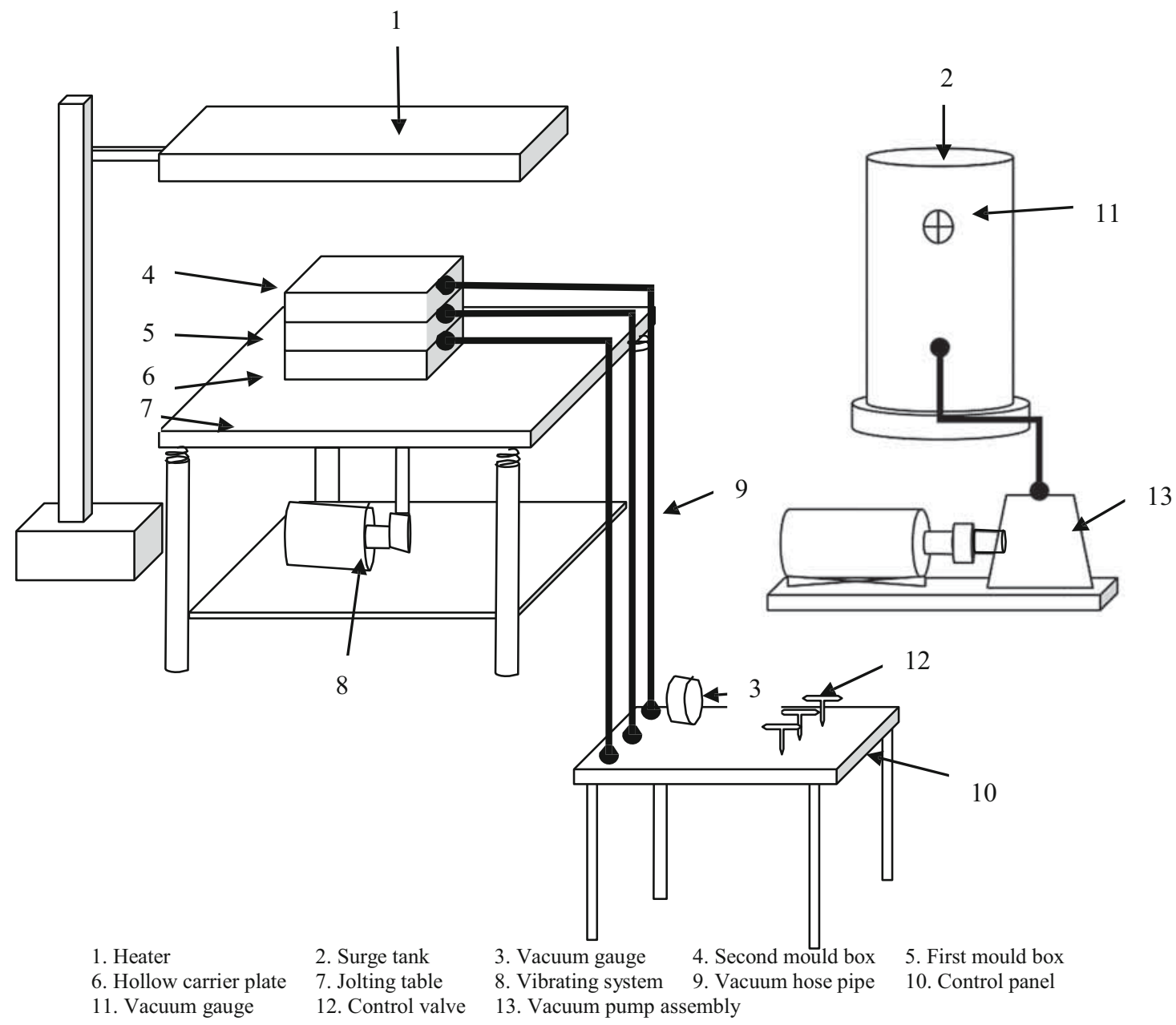

Figure 2. Schematic of VM set-up [8]. 


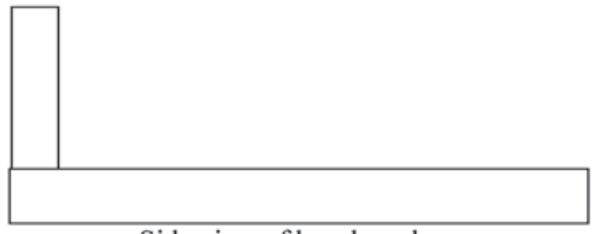

Side view of benchmark

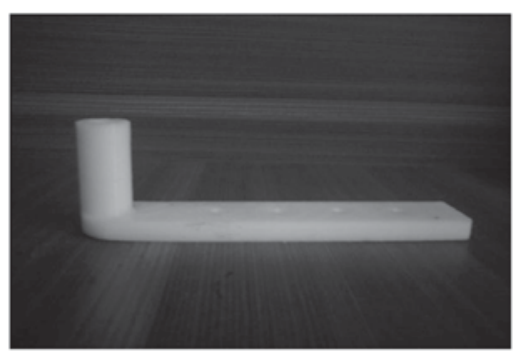

ABS part

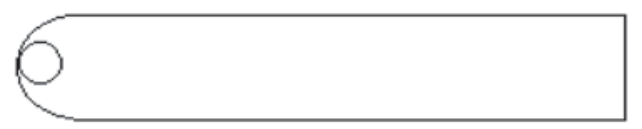

Top view of benchmark

Figure 3. Different views of component manufactured from FDM [1].

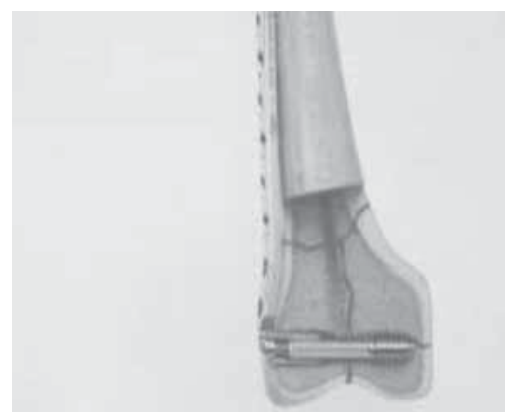

Figure 4. Distal femoral fractures [8].

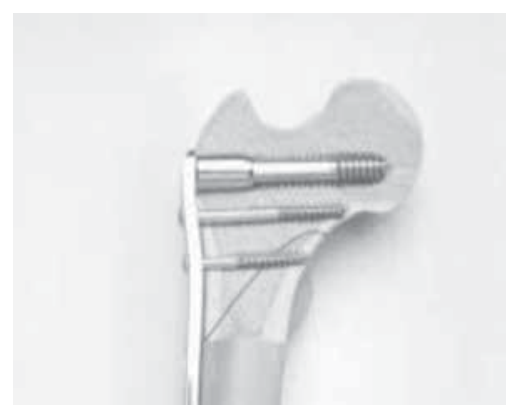

Figure 5. Sub-trochanteric fracture [8]. should be noted that this may be a constraint from stirring set-up point of view. Hence the range of $\mathrm{Al}_{2} \mathrm{O}_{3}$ particles in $\mathrm{Al}$ was selected as 5-10\%. A similar trend of hardness was observed for sand grain size of 50-70. As regards vacuum pressure below $250 \mathrm{~mm}$ of $\mathrm{Hg}$ is concerned no sufficient vacuum was available for tight/sound cavity formation and above $400 \mathrm{~mm}$ of $\mathrm{Hg}$ the plastic sheet gets torn off.

Therefore for final experimentation the composition of Al with $\mathrm{Al}_{2} \mathrm{O}_{3}$ (of 150 AFS no.) selected is $\mathrm{Al}-5 \%$ $\mathrm{Al}_{2} \mathrm{O}_{3}, \mathrm{Al}-7.5 \% \quad \mathrm{Al}_{2} \mathrm{O}_{3}$ and $\mathrm{Al}-10 \% \mathrm{Al}_{2} \mathrm{O}_{3}$. After sufficient manual mixing was done, the composite (in slurry form) was reheated to a fully liquid state and then automatic mechanical mixing was carried out for about $10 \mathrm{~min}$ at a normal stirring rate of $600 \mathrm{rpm}$ as in a commercial SC process. After conducting the pilot experimentation it has been observed that input parameters like vacuum pressure, grain size and $\mathrm{Al}_{2} \mathrm{O}_{3}$ composition have effect on the microhardness of component prepared. For final experimentation the selected parameters are shown in table 1.

For the optimization process, design of final experimentation was made according to Taguchi's L9 orthogonal array (see table 2). Table 3 shows the observation of final experimentation for microhardness based upon Taguchi L9 orthogonal array. Here $\mathrm{H} 1, \mathrm{H} 2$ and $\mathrm{H} 3$ are three repetitions of the experiment conducted. Figures 7 and 8 show casting with a gate, riser attachment and the finished DCS plate, respectively.

\section{Results and discussion}

The cast component hardness depends upon percentage composition of $\mathrm{Al}_{2} \mathrm{O}_{3}$, moulding sand AFS no. and vacuum pressure imposed. Signal to noise $(S / N)$ ratio curves have been drawn to obtain the optimum settings. Table 4 shows the $S / N$ ratio for microhardness. These results are for maximum the better type case and valid for $95 \%$ level of confidence.

Figures 9, 10 and 11 show variation of $S / N$ ratio and microhardness with respect to percentage composition, grain size and vacuum pressure, respectively. As observed from figures $9-11$ the maximum hardness and $S / N$ ratio was 


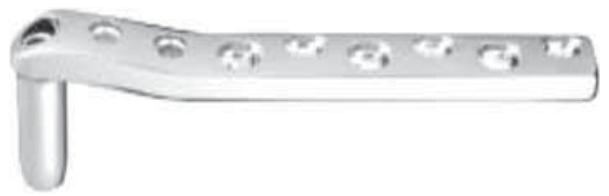

Figure 6. $3 \mathrm{D}$ view of DCS.

Table 1. Process parameters and their levels.

\begin{tabular}{lccc}
\hline & \multicolumn{3}{c}{ Levels } \\
\cline { 2 - 4 } Parameter & 1 & 2 & 3 \\
\hline Percentage composition $\left(\% \mathrm{Al}_{2} \mathrm{O}_{3}\right)$ & 5 & 7.5 & 10 \\
Vacuum pressure (mm of $\mathrm{Hg})$ & 300 & 350 & 400 \\
Grain size of silica (AFS no.) & 50 & 60 & 70 \\
\hline
\end{tabular}

attained with $5 \% \mathrm{SiC}$, AFS no. 60 and $300 \mathrm{~mm}$ of $\mathrm{Hg}$ vacuum pressure. The reason for maximum hardness at $5 \%$ $\mathrm{Al}_{2} \mathrm{O}_{3}$ composition may be a constraint from the selection of SC process parameters. As a matter of fact with increase in composition of ' $\mathrm{Al}_{2} \mathrm{O}_{3}$ ', hardness must increase, but in the present case this decrease may be because of settlement

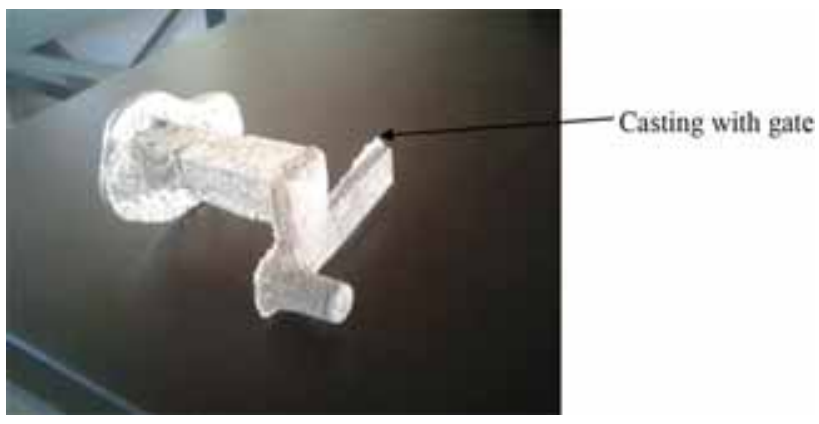

Figure 7. Casting with gate, riser attachment.

of these abrasives in castings downward, because of improper mixing or in other words selection of rpm of stirring may be one of the constraint of the SC process used. In actual field environment one cannot increase the rpm of the stirrer beyond a limit while handling the molten metal, because the molten metal may spill out and may cause some accident.

The increase in hardness by using grain size from ASF no. 50 to 60 is but obvious as smaller grains of sand result in better cooling rate and hence more hardness and further

Table 2. The control log of the experimentation.

\begin{tabular}{lccc}
\hline Sl. no. & Composition $(\%)$ & Grain size (AFS no.) & Vacuum pressure (mm of Hg) \\
\hline 1 & $\mathrm{Al}-5 \% \mathrm{Al}_{2} \mathrm{O}_{3}$ & 50 & 300 \\
2 & $\mathrm{Al}-5 \% \mathrm{Al}_{2} \mathrm{O}_{3}$ & 60 & 350 \\
3 & $\mathrm{Al}-5 \% \mathrm{Al}_{2} \mathrm{O}_{3}$ & 70 & 400 \\
4 & $\mathrm{Al}-7.5 \% \mathrm{Al}_{2} \mathrm{O}_{3}$ & 50 & 350 \\
5 & $\mathrm{Al}-7.5 \% \mathrm{Al}_{2} \mathrm{O}_{3}$ & 60 & 400 \\
6 & $\mathrm{Al}-7.5 \% \mathrm{Al}_{2} \mathrm{O}_{3}$ & 70 & 300 \\
7 & $\mathrm{Al}-10 \% \mathrm{Al}_{2} \mathrm{O}_{3}$ & 50 & 400 \\
8 & $\mathrm{Al}-10 \% \mathrm{Al}_{2} \mathrm{O}_{3}$ & 60 & 300 \\
9 & $\mathrm{Al}-10 \% \mathrm{Al}_{2} \mathrm{O}_{3}$ & 70 & 350 \\
\hline
\end{tabular}

Table 3. Observations of final experimentation.

\begin{tabular}{|c|c|c|c|c|c|c|}
\hline \multirow[b]{2}{*}{ S1. no. } & \multirow[b]{2}{*}{ Composition } & \multirow[b]{2}{*}{ Grain size (AFS no.) } & \multirow[b]{2}{*}{ Vacuum pressure (mm of $\mathrm{Hg}$ ) } & \multicolumn{3}{|c|}{ Microhardness (HV) } \\
\hline & & & & H1 & $\mathrm{H} 2$ & H3 \\
\hline 1 & $\mathrm{Al}-5 \% \quad \mathrm{Al}_{2} \mathrm{O}_{3}$ & 50 & 300 & 54 & 52 & 54 \\
\hline 2 & $\mathrm{Al}-5 \% \quad \mathrm{Al}_{2} \mathrm{O}_{3}$ & 60 & 350 & 60 & 62 & 59 \\
\hline 3 & $\mathrm{Al}-5 \% \quad \mathrm{Al}_{2} \mathrm{O}_{3}$ & 70 & 400 & 56 & 59 & 60 \\
\hline 4 & $\mathrm{Al}-7.5 \% \quad \mathrm{Al}_{2} \mathrm{O}_{3}$ & 50 & 350 & 54 & 52 & 50 \\
\hline 5 & $\mathrm{Al}-7.5 \% \quad \mathrm{Al}_{2} \mathrm{O}_{3}$ & 60 & 400 & 57 & 59 & 58 \\
\hline 6 & $\mathrm{Al}-7.5 \% \quad \mathrm{Al}_{2} \mathrm{O}_{3}$ & 70 & 300 & 63 & 61 & 62 \\
\hline 7 & $\mathrm{Al}-10 \% \mathrm{Al}_{2} \mathrm{O}_{3}$ & 50 & 400 & 50 & 49 & 51 \\
\hline 8 & $\mathrm{Al}-10 \% \quad \mathrm{Al}_{2} \mathrm{O}_{3}$ & 60 & 300 & 61 & 60 & 63 \\
\hline 9 & $\mathrm{Al}-10 \% \quad \mathrm{Al}_{2} \mathrm{O}_{3}$ & 70 & 350 & 54 & 53 & 56 \\
\hline
\end{tabular}




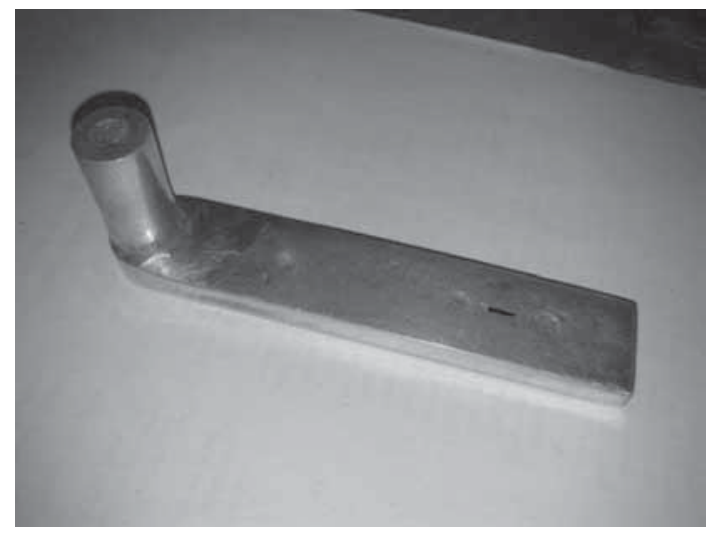

Figure 8. Finished product (DCS plate).

Table 4. $S / N$ ratio for microhardness (HV)

\begin{tabular}{lccclc}
\hline S1. no. & H1 & H2 & H3 & $S / N$ ratio & Average \\
\hline 1 & 54 & 52 & 54 & 34.53583 & 53.33 \\
2 & 60 & 62 & 59 & 35.60563 & 60.33 \\
3 & 56 & 59 & 60 & 35.30704 & 58.33 \\
4 & 54 & 52 & 50 & 34.30721 & 52.0 \\
5 & 57 & 59 & 58 & 35.26598 & 58.0 \\
6 & 63 & 61 & 62 & 35.84557 & 62.0 \\
7 & 50 & 49 & 51 & 33.97592 & 50.0 \\
8 & 61 & 60 & 63 & 35.7486 & 61.33 \\
9 & 54 & 53 & 56 & 34.69454 & 54.33 \\
\hline
\end{tabular}

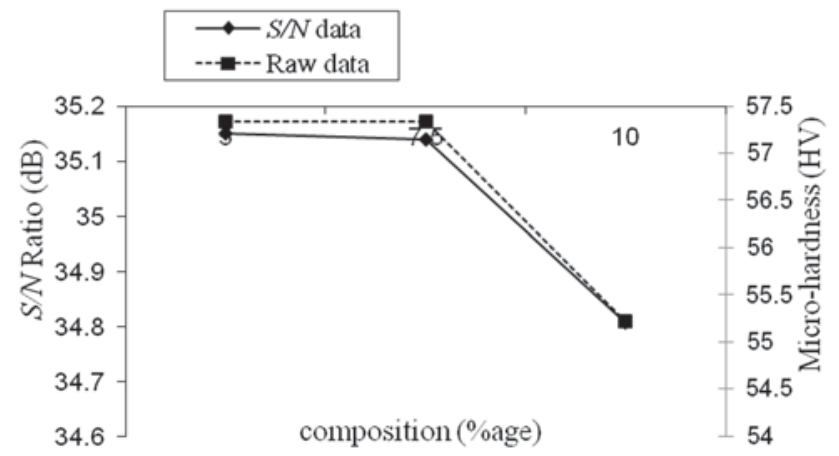

Figure 9. Variation of $S / N$ ratio and microhardness with respect to percentage composition.

decrease from 60 to 70 may be again an experimentation constraint. Similarly, as regards vacuum pressure, $300 \mathrm{~mm}$ of $\mathrm{Hg}$ vacuum pressure gave better results for the following reason: with increase in vacuum pressure above $300 \mathrm{~mm}$ of $\mathrm{Hg}$, it has been observed that the effect of vacuum was not limited to providing mould cavity stability but in fact molten metal was being sucked into the vacuum chamber. Confirmatory experiments were conducted at these settings and results of the study show that percentage improvement in microhardness is $3.4 \%$. In order to ascertain these results,

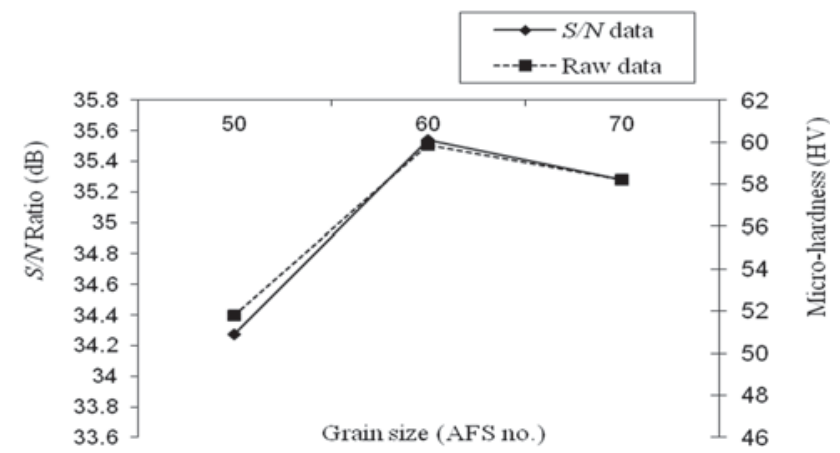

Figure 10. Variation of $S / N$ ratio and microhardness with respect to grain size (AFS no.).

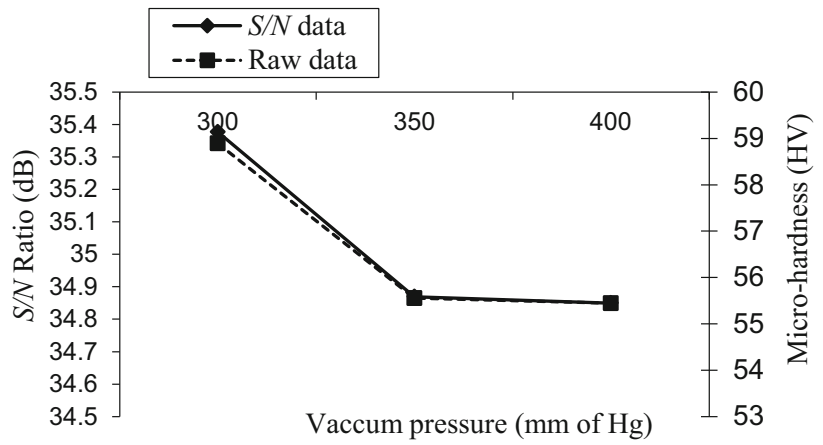

Figure 11. Variation of $S / N$ ratio and microhardness with respect to vacuum pressure ( $\mathrm{mm}$ of $\mathrm{Hg}$ ).

cooling rate and microstructure analysis (see figure 12) have been performed for all nine sets of experiments as per table 2 .

As observed from figure 12 for microstructure of experiment no. 1 , the peaks are sharp and connected while the pits are of different depths and sizes. Also pits remain isolated and unconnected. However, in experiment no. 6 the sample has a fine microstructure, irregular in size and shape. The surface is dotted with fine peaks and pits of different sizes. Pits are relatively round and their size changes along the depth. Since the solidification rate is dependent on the dropping of temperature in a given interval of time, the rate of solidification of nine sets of castings was determined from the cooling curves generated during the experimentation by an IR thermometer. Table 5 shows the rate of solidification and hardness values for the castings prepared.

As observed from table 5 for experiment no. 6 , maximum hardness and high solidification/cooling rate are observed. It should be noted that for experiment no. 6, less pitting is observed (see figure 12). Hence it can be ascertained that the input parameters (namely, percentage composition of $\mathrm{Al}-\mathrm{Al}_{2} \mathrm{O}_{3}$, grain fineness no. of silica sand used in $\mathrm{VM}$ process and vacuum pressure) influence the microhardness of the MMC prepared. For better understanding of this fact, percentage contribution of various input parameters that affect the microhardness of the MMC has been 


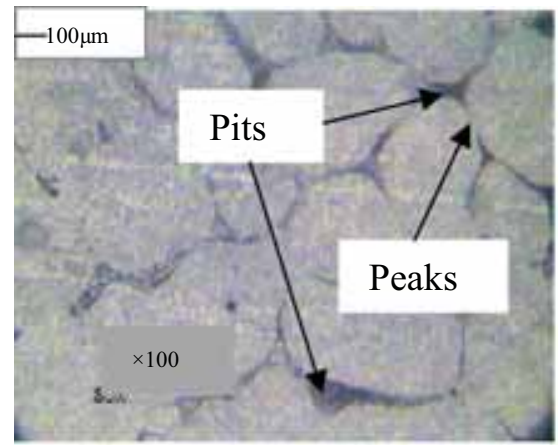

(a)

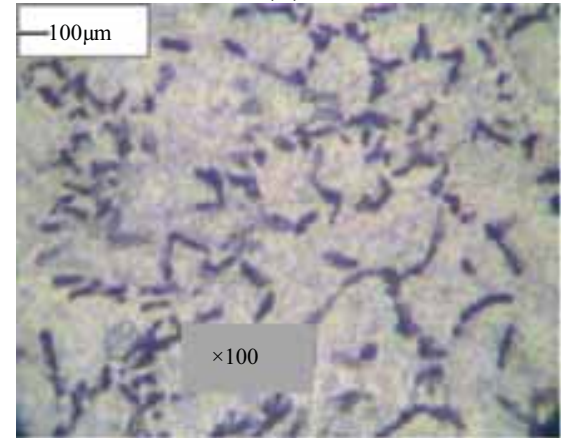

(d)

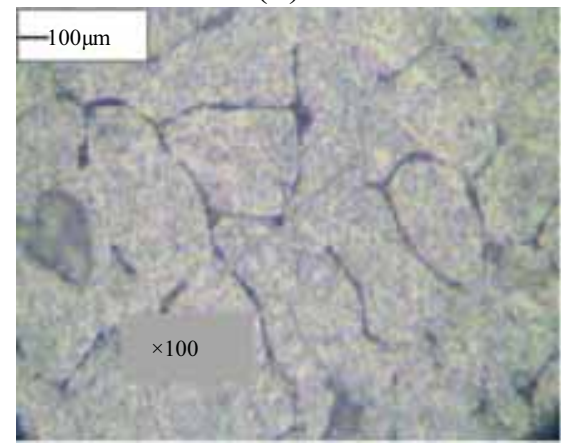

(g)

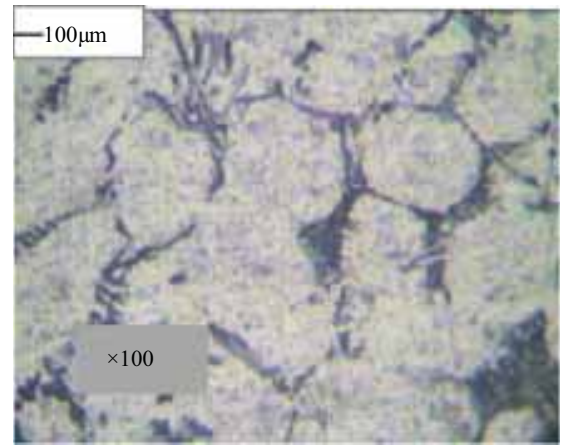

(b)

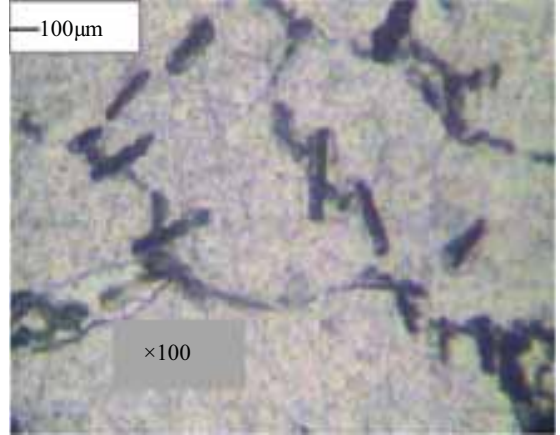

(e)

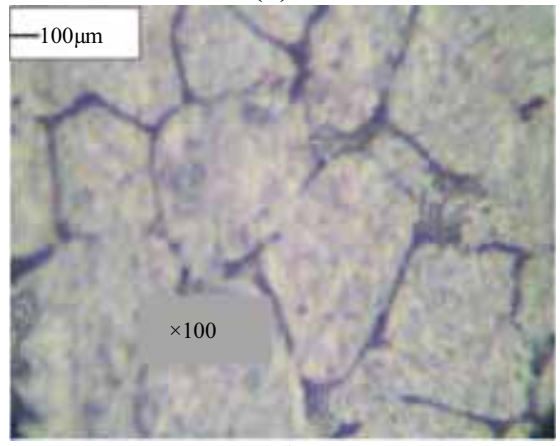

(h)

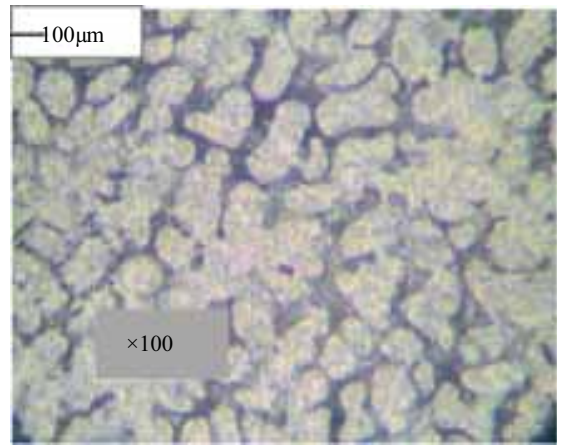

(c)

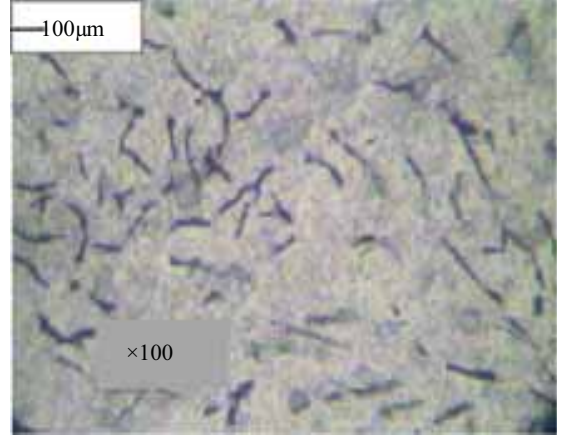

(f)

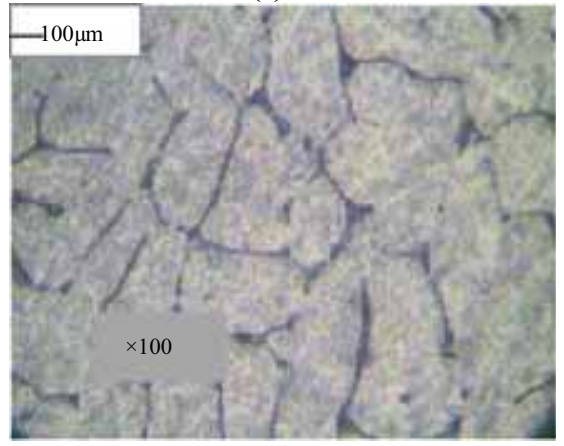

(i)

Figure 12. Microstructure for nine sets of experiments (as per table 2). (a) Microstructure for experiment 1, (b) microstructure for experiment 2, (c) microstructure for experiment 3, (d) microstructure for experiment 4, (e) microstructure for experiment 5, (f) microstructure for experiment 6, (g) microstructure for experiment 7, (h) microstructure for experiment 8, (i) microstructure for experiment 9 .

Table 5. Effect of solidification rate on microhardness.

\begin{tabular}{lccccc}
\hline S1. no. & Percentage composition & Grain size (AFS no.) & Vacuum pressure & Microhardness & Solidification rate $(\mathrm{d} T / \mathrm{d} t)$ \\
\hline 1 & 5 & 50 & 300 & 54 & 1.1667 \\
2 & 5 & 60 & 350 & 60 & 2.0 \\
3 & 5 & 70 & 400 & 56 & 1.867 \\
4 & 7.5 & 50 & 350 & 54 & 1.25 \\
5 & 7.5 & 60 & 400 & 57 & 1.96 \\
6 & 7.5 & 70 & 400 & 53 & 2.3 \\
7 & 10 & 50 & 300 & 61 & 0.78 \\
8 & 10 & 60 & 350 & 54 & 2.13 \\
9 & 10 & 70 & & \\
\hline
\end{tabular}


Table 6. Percentage contribution of various inputs for microhardness.

\begin{tabular}{lc}
\hline Parameters & Percentage contribution $(\%)$ \\
\hline Composition & 6.29 \\
Grain size & 74.01 \\
Vacuum pressure & 14.73 \\
Error & 4.95 \\
\hline
\end{tabular}

calculated (see table 6). The error contribution below 5\% highlights that the process is under controlled conditions and hence a judicious selection of input parameters was made in this experiment design. In other words the effect of any other input parameters for contribution towards microhardness is below $5 \%$.

\section{Conclusions}

In this case study a DCS plate has been successfully prepared by combining FDM-based patterns and VM, SC processes. The optimum values of three different input parameters and their effect on microhardness of DCS plate manufactured according to the combined process have been highlighted. Results of the study suggest that the best setting for maximum microhardness is the following: composition of $\mathrm{Al}_{2} \mathrm{O}_{3} 5 \%$, AFS no. 60 and vacuum pressure 300 $\mathrm{mm}$ of $\mathrm{Hg}$. Further, as regards microhardness of MMC prepared by combining FDM-based patterns with VM and $\mathrm{SC}$ the percentage contribution of $\mathrm{Al}_{2} \mathrm{O}_{3}$ composition, AFS no. and vacuum pressure is $6.2 \%, 74 \%$ and $14.73 \%$, respectively. Hence for controlling the hardness with the combined process of VM, SC using FDM-based patterns the maximum focus should be on selection of AFS no. of silica grain used. Finally the current study suggests that it might be possible to manufacture DCS in the proposed fashion to obtain the best microhardness.

\section{Acknowledgements}

The authors are thankful to AICTE, New Delhi, for financial support.

\section{References}

[1] Singh R 2013 Process capability analysis of vacuum moulding for development of $\mathrm{Al}-\mathrm{Al}_{2} \mathrm{O}_{3} \mathrm{MMC}$. J. Inst. Eng. (India): Ser. C 94(1): 93-97

[2] Singh K and Singh R 2013 Experimental investigations for statistically controlled vacuum moulding solutions of Al-SiC MMC. Appl. Mech. Mater. 330: 91-95

[3] Singh R and Singh G 2013 Replication of FDM based patterns via vacuum moulding. (Saarbrücken, Germany: Lambert Academic Publishing AG \& Co. KG)

[4] Singh R, Singh J and Singh J 2012 Macro-model for development of $\mathrm{Al}-\mathrm{Al}_{2} \mathrm{O}_{3}$ metal matrix composite with vacuum moulding: designed experiments. J. Inst. Eng. (India): Ser. C 93(4): 325-330

[5] Gu P and Li L 2002 Fabrication of biomedical prototypes with locally controlled properties using FDM. Ann. CIRP 51(1): 181-184

[6] Gibson I, Cheung L K, Chow S P, Cheung W L, Beh S L, Savalani M M and Lee S H 2006 The use of rapid prototyping to assist medical applications. Rapid Prototyping $J$. 12: $53-58$

[7] Singh R and Singh J 2013 Macro-model for development of Al-SiC metal matrix composite with vacuum moulding: designed experiments. Mater. Sci. Forum 751: 21-26

[8] Singh G 2013 Experimental investigations for replication of FDM based patterns by vacuum moulding in biomedical applications. MTech Thesis, Punjab Technical University, Jalandhar, India

[9] Bakhtiyarov S I, Overfelt R, Black M G and Weiss D J 2005 Design and $\mathrm{V}$-process production of cast magnesium component. Trans. Am. Foundrymen's Soc. 113: 879-886

[10] Kumar S, Kumar P and Shan H S 2007 Effect of process parameters on the solidification time of $\mathrm{Al}-7 \% \mathrm{Si}$ alloy castings produced by VAEPC process. Mater. Manuf. Process. 22(7-8): 879-886

[11] Singh R and Singh G 2015 Investigations of Al-SiC MMC prepared by vacuum moulding assisted stir casting. J. Manuf. Process. 19: 142-147

[12] Singh R, Podder D and Singh S 2015 Effect of single, double and triple particle size $\mathrm{SiC}$ and $\mathrm{Al}_{2} \mathrm{O}_{3}$ reinforcement on wear properties of AMC prepared by stir casting in vacuum mould. Trans. Indian Inst. Met. 68(5): 791-797

[13] Thrimurthulu K, Pandey P M and Reddy N V 2004 Optimum part deposition orientation in fused deposition modeling. Int. J. Mach. Tools Manuf. 44: 585-594 